\title{
THE EFFECT OF CATION AND ANION SPECIES ON THE TRANSITION AND ADSORPTION BEHAVIORS OF THERMOSENSITIVE SULFOBETAINE GEL- BASED ADSORBENT
}

\author{
Eva Oktavia Ningrum ${ }^{1 *}$, Shuji Sakohara ${ }^{2}$, Takehiko Gotoh $^{3}$, Suprapto ${ }^{1}$, Nurlaili Humaidah ${ }^{1}$ \\ ${ }^{1}$ Department of Industrial Chemical Engineering, Faculty of Vocational Studies, Institut Teknologi \\ Sepuluh Nopember, Kampus ITS Sukolilo, Surabaya, 60111, Indonesia \\ ${ }^{2}$ National Institute of Technology Niihama College, Yagumocho, 7-1, Niihama-shi, Ehime Prefecture \\ 792-8580, Japan \\ ${ }^{3}$ Department of Chemical Engineering, Graduate School of Engineering, Hiroshima University, \\ Kagamiyama 1-4-1, Higashi-Hiroshima, 739-8527, Japan
}

(Received: July 2018 / Revised: October 2018 / Accepted: April 2019)

\begin{abstract}
This study was conducted to examine the ion absorption behavior of zwitterionic sulfobetaine type $N, N$-dimethyl(acrylamidopropyl) ammonium propane sulfonate (DMAAPS) gels. In addition, it also examines the effect of salt solution concentration and ionic strength on the poly(DMAAPS) transition behavior in different salt solutions. The adsorption behavior of the gel in nitrate, chloride and sulfate solutions was found to be a strong function of the valence. The number of ions adsorbed onto the DMAAPS gel increases in line with the increase of cations valences, with the order of adsorption being $\mathrm{Zn}^{2+}>\mathrm{Ni}^{2+}>\mathrm{Na}^{+}, \mathrm{K}^{+}$. The level of ion adsorption onto the DMAAPS gel in various salt solutions with common cations of $\mathrm{Na}^{+}, \mathrm{K}^{+}$and $\mathrm{Zn}^{2+}$ shows a tendency in the order of $\mathrm{NO}_{3}{ }^{-}>\mathrm{Cl}^{-}>\mathrm{SO}_{4}{ }^{2-}$. Comparing the effect of the anion and cation of the same charge on the number of ions adsorbed, the anion species effect is greater than that of the cation species at all concentrations. At first, the transition temperature of the poly(DMAAPS) within the salt solution increases. However, it then decreases when the ions adsorbed onto the DMAAPS gel increase and reach a maximum level. On the other hand, the level depends on the species and ion concentration. Therefore, it can be concluded that the maximum level of ions adsorbed can be simply ascertained by determining the transition temperature.
\end{abstract}

Keywords: Ion-adsorption; Sulfobetaine; Transition temperature

\section{INTRODUCTION}

In responding to small changes in physical or chemical stimuli, polymer gels experience a collapsed phase transition. This could, therefore, be a promising system to be applied as stimulisensitive or smart polymers. The physical changes include ones in temperature, electricity, magnetic fields, light or pressure, while the chemicals changes include ones in $\mathrm{pH}$, solvent composition and ionic strength. Various studies have been conducted regarding the myriad of related properties, structures and applications. One of these was research conducted by Baldino et al. (2016), which employed supercritical gel as the scaffold to examine the natural and biocompatible silk fibroin SF-based aerogel drying process for nanomedicine. Other previous research was conducted by Todaro et al. (2016), who studied the synthesis of xyloglucan hydrogels by irradiated e-beam to control molecular weight in order to produce scaffolds used in

\footnotetext{
*Corresponding author's email: eva-oktavia@chem-eng.its.ac.id, Tel. +62-813-35233410
}

Permalink/DOI: https://doi.org/10.14716/ijtech.v10i3.2899 
tissue engineering. Recently, polymer gel incorporating the polyzwitterionic species has become popular and attracted much attention in scientific research due to its specific, sensitive and instantaneous responsiveness. Zwitterionic betaine has either anionic or cationic active groups, both of which have the same unit in polymeric repeat (Ningrum et al., 2017b). In addition, between the two active groups, there are also an alkylene group and a neutral overall charge of the molecule. The ion exchange selectivity of zwitterionic betaine can be improved by combining its charged functional groups, which are opposite each other in a molecule since it chemically bonds with both positive and negative charges, located in the same repeating unit (Nesterenko et al., 2009).

The use of absorbent in the form of thermosensitive gel based on zwitterionic betaine is one of the most recent ways of separating heavy metals ions in aqueous solution. Such absorbent has selectivity toward the ions as the consequence of the interaction between the positive and negative charges of the chain, making it the most effective way of overcoming the heavy metal contamination in the aquatic environment. In addition, zwitterionic betaine also has the ability to simultaneously bond the anions and cations in liquid waste. A wide range of thermosensitive polymers has been developed and evaluated for their ability to recover metal ions from aqueous media, most of which are copolymers containing poly( $N$-isopropylacrylamide) (polyNIPAAm), and monomers bearing complexing groups. The thermosensitive moiety used is usually polyNIPAAm, and the monomer-bearing complexing groups have sorption properties (Graillot et al., 2012).

A number of papers have been published by Nonaka et al. (2003) concerning the use of thermosensitive copolymer hydrogels with phosphonium groups. These hydrogels have been proven to be able to absorb a great quantity of water, as well as to conduct a high level of antibacterial activities, which are affected by the solution temperature. The capacities of the divalent and trivalent heavy metal retention of two cross-linked polyzwitterionic carboxybetaine structures based on 4-vinylpyridine: divinylbenzene macromolecular supporting gel and porous type were investigated by Neagu et al. (2010). In aqueous solution, both zwitterionic ion exchanger types synthesized were found to have retained metal cations and anions; however, no retention capacities have been obtained in the alkaline earth metal solutions. Another study by Ning et al. (2013) was conducted to examine the poly(DMAAPS) synthesis condition on the polymer yield, intrinsic viscosity, molecular weight and gel fraction through the variation of monomer concentration, with and without the use of an organic cross-linker.

Kusrini et al. (2018b) separated textile dyes from aqueous solution by using adsorbents. Heating, acid activation and impregnation methods were used to prepare graphite/ $\mathrm{Fe}_{3} \mathrm{O}_{4}$ composites with different graphite to $\mathrm{Fe}_{3} \mathrm{O}_{4}$ ratios. The graphite/ $\mathrm{Fe}_{3} \mathrm{O}_{4}(1: 1 \mathrm{w} / \mathrm{w} \%, 2 \mathrm{M} \mathrm{HCl})$ composite was optimized as the adsorbent of the textile dyes. The capacity of the dyes adsorbed is affected by the electrostatic interaction of the adsorbent, which is built between the dyes and the functional groups. Kusrini et al. (2019) have also reported that the utilization of the adsorption technique in separating mercury from liquid hydrocarbon is cost-effective and economical. They investigated the maximum capacity of the mercury adsorbed from the liquid hydrocarbon was as high as 0.93 ng/g using the SnOx-impregnated clinoptilolite. This amount is higher than the use of natural clinoptilolite, which achieved a maximum amount of mercury adsorption of $0.43 \mathrm{ng} / \mathrm{g}$. In addition, based on the structure and morphology of $\mathrm{SnOx}$, an analysis was also made of the SnOx coated on the surface of the clinoptilolite, making the surface rougher and with a smaller pore size and volume than with the use of natural clinoptilolite Kusrini et al. (2019). This adsorption technique was also used by Kusrini et al. (2018a) to remove commercial lanthanide ions from aqueous solution by using adsorbent in the form of activated carbon obtained from a banana peel, which has the highest iodine absorbance of $572.2 \mathrm{mg} / \mathrm{g}$. 
Our previous study explored an interesting correlation between the transition behavior of sulfobetaine $N, N$-dimethyl(acrylamidopropyl)ammonium propane sulfonate [poly(DMAAPS)], swelling behavior and the adsorption behavior of ions onto DMAAPS gels (Ningrum et al., 2014). The adsorption ability of DMAAPS towards metal ions was found to be strongly dependent on the charge groups forming an ionic association (intra- and/or inter-chain association) with the metal ions, which also significantly affected their swelling and transition behavior. The intraand/or inter-chain association was disrupted and dissociated by the addition of salt solution, resulting in chain expansion and an increase in swelling degree of DMAAPS gel. It was also found that the higher the valence of cations of the salt solution, the lower the level of swelling due to the formation of cations between the polymer chains. Furthermore, cross-linker concentration also determines the type of chain association that dominates in the DMAAPS network. Considering the sensitive characteristic of sulfobetaine DMAAPS to the ions, in this work DMAAPS gel adsorption behavior in the presence of various salt solutions is investigated. The study also describes the salt solution concentration and how ionic strength affects the transition behavior of poly(DMAAPS) in different salt solutions.

\section{EXPERIMENTAL PROCEDURE}

\subsection{Materials}

Several materials were used in the research, including 1,3-propanesultone (PS) bought from Tokyo Chemical Industry Co., Ltd, $N, N$-dimethylaminopropylacrylamide (DMAPAA) supplied by KJ. Chemicals Co., Ltd, together with $N, N^{\prime}$-methylenebisacrylamide (MBAA), $N, N, N^{\prime}, N^{\prime}-$ tetramethylethylenediamine (TEMED) and ammonium peroxodisulfate (APS), both purchased from Sigma-Aldrich Co. (USA). Some of the materials were purchased from and supplied by different companies and were used either with or without purification. $N, N$ dimethylaminopropylacrylamide (DMAPAA) was the only material used after purification by vacuum distillation. Therefore, the other materials were used without going through any purification. In addition, acetonitrile was purchased from Kanto Chemical Co., Inc and acetone from Nacalai Tesque, Inc., which were used as the purification solvents.

\subsection{Synthesis of DMAAPS}

The synthesis of DMAAPS involved the ring-opening reaction method of DMAPAA and PS. This method was also used in our previous research (Ningrum et al., 2017a). In this step, $75 \mathrm{~g}$ PS and $75 \mathrm{~g}$ acetonitrile were mixed and stirred continuously at $30^{\circ} \mathrm{C}$ for $90 \mathrm{~min}$. The mixture was then added to a mixture of $100 \mathrm{~g}$ DMAPAA and $200 \mathrm{~g}$ acetonitrile and stirred continuously for 16 hours before being left for two days. Finally, filtration was performed to obtain the precipitated white crystals of DMAAPS, which were then washed using $500 \mathrm{ml}$ acetone, and dried for at least $24 \mathrm{~h}$ in a vacuum oven.

\subsection{Synthesis of poly(DMAAPS)}

This synthesis was started by preparing poly(DMAAPS) obtained from free radical polymerization. The polymerization was accelerated by using TEMED and initiated by using APS (Ningrum et al., 2015). The concentrations of each material used in the preparation were $500 \mathrm{mmol} / \mathrm{L}$ of DMAAPS, $2 \mathrm{mmol} / \mathrm{L}$ of TEMED, and $2 \mathrm{mmol} / \mathrm{L}$ of APS. DMAAPS and TEMED were first dissolved in $100 \mathrm{ml}$ of deionized water and placed into a separable flask. Nitrogen was then used to purify this solution, with the aim of removing the dissolved oxygen. After purification, the solution was then added to $20 \mathrm{ml}$ of APS solution, which had also been purified to remove the dissolved oxygen. The polymerization was conducted for $6 \mathrm{~h}$ at $50^{\circ} \mathrm{C}$ in a nitrogen atmosphere. The result of the polymerization was then purified using dialysis for 7 days using a membrane with a molecular weight cut off of 12000-14000 (Cellu Step T3, Membrane Filtration Product, Inc.). After the dialysis, the polymer was then dried in an oven for $24 \mathrm{~h}$ The poly(DMAAPS) synthesis apparatus is shown in Figure 1. 


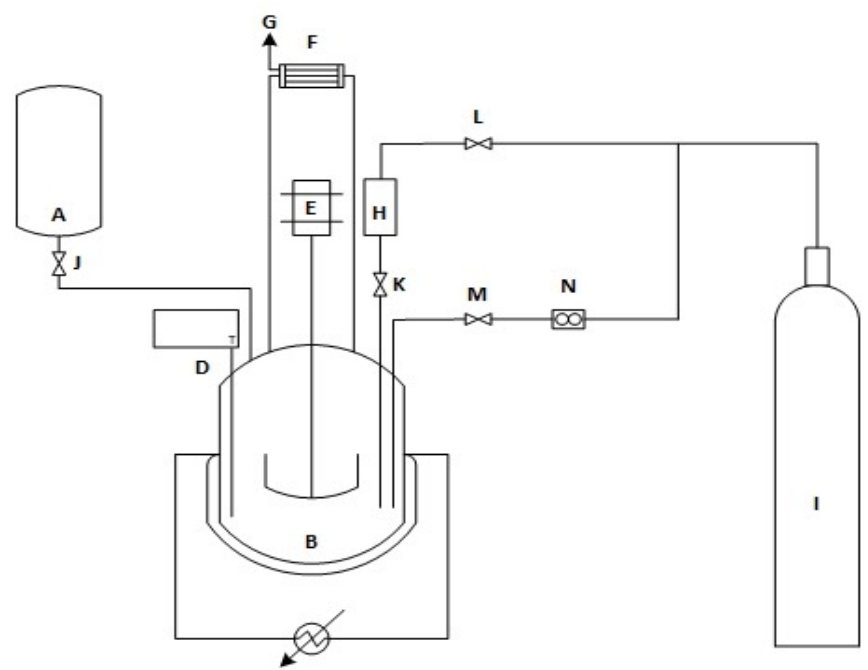
A. Monomer feed tank
G. $\mathrm{N}_{2}$ purge
B. Polymerization batch reactor
H. Initiator feed tank
C. Heater
I. $\mathrm{N}_{2}$ gas
D. Temperature controler
JKLM. Valves
E. Stirrer
N. Flowmeter
F. Condenser

Figure 1 Poly(DMAAPS) experiment set-up

\subsection{Synthesis of DMAAPS gel}

In this synthesis, DMAAPS hydrogels were prepared in the same way as the preparation of the polymer in the previous synthesis. However, in this preparation, $N, N^{\prime}$-methylenebisacrylamide (MBAA) was used as the cross-linker. A separable flask was used to conduct the DMAAPS gel synthesis, with glass tubes inside with a diameter of $2 \mathrm{~mm}$ and length of $30 \mathrm{~mm}$. The DMAAPS, TEMED and MBAA were then mixed and an APS solution of $20 \mathrm{ml}$ added, which led to DMAAPS gel formation. The nitrogen was purged continuously for $6 \mathrm{~h}$ at $50^{\circ} \mathrm{C}$. The gels formed were dried slowly over several days and then cut into small pieces, washed, dried in an oven, and ground. Subsequently, they were sieved using a strainer of greater than 180 mesh size. Table 1 lists the DMAAPS preparation conditions.

Table 1 Preparation conditions of DMAAPS gel

\begin{tabular}{llc}
\hline & & Concentration $\left(\mathrm{mol} / \mathrm{m}^{3}\right)$ \\
\hline Monomer & : DMAAPS & 1000 \\
Linker & : MBAA & 30 \\
Accelerator & : TEMED & 10 \\
Initiator & : APS & 0.5 \\
\hline
\end{tabular}

Synthesis temperature: $50^{\circ} \mathrm{C}$, Solvent: water, Reaction Time: $6 \mathrm{~h}$

\subsection{Measurement of poly(DMAAPS) Transition Temperature}

The transmittance change at $600 \mathrm{~nm}$ was measured using a spectrophotometer supplemented by a temperature control system in order to characterize the Upper Critical Solution Temperature (UCST) of the DMAAPS through the polymer solution. When the temperature is above the UCST, the solution becomes transparent due to the nature of the polymer being soluble in a solution. 
However, when the temperature is below the UCST, the solution changes color to opaque or milky white, and it becomes cumulated and insoluble.

\subsection{Measurement of the Cation and Anion Adsorption Level in Salt Solution onto DMAAPS Gels}

The following procedures were taken to conduct the adsorption. First, the ground DMAAPS gel $(1 \mathrm{~g})$ was added to $20 \mathrm{ml}$ of salt solution with the desired concentration in a glass bottle. The bottle was then put into a water bath at $50^{\circ} \mathrm{C}$ and the solution containing the gels was stirred for $12 \mathrm{~h}$ in order for the gels to swell and reach the equilibrium adsorption. The gels from the solution were removed to obtain a sample which aimed to determine the sample concentration by using a centrifuge at $3500 \mathrm{rpm}$ and a syringe filter $(0.45 \mu \mathrm{m}$, Toyo Roshi Kaisha, Ltd). The cation and anion concentration was then characterized by ion chromatography. The cation analysis was carried out using a $4.6 \mathrm{~mm}$ (ID) $\times 10 \mathrm{~cm}$ (L) TSKgel IC-Cation 1/2 HR column (Tosoh Corp.) with $2 \mathrm{mmol} / \mathrm{L}$ of $\mathrm{HNO}_{3}$ as a mobile phase. In addition, the anion measurement was performed using a $4.6 \mathrm{~mm}$ (ID) $\times 100 \mathrm{~mm}$ (L) Shim-pac IC-A1column (Shimadzu Corp.) with $2.5 \mathrm{mmol} / \mathrm{L}$ and $\mathrm{pH} 4.0$ of phthalic acid as a mobile phase.

The following formula was used to calculate the number of ions adsorbed obtained from the cation or anion concentration in the solution, before and after adsorption:

$$
Q=\frac{\left(C_{0}-C\right) x V}{m}
$$

$Q$ is the cations or anions adsorbed, $C_{0}$ is the cation or anion concentration in the initial solution; $C$ is the cation or anion concentration in the aqueous solution after the adsorption had been conducted for a certain period; $V$ is the volume of the aqueous phase; and $m$ is the weight of the dry sample gels.

\section{RESULTS AND DISCUSSION}

\subsection{Transition Behaviors of poly(DMAAPS)}

\subsubsection{Effect of anion species}

Figure 2 shows the behavior of the poly(DMAAPS) transition with a concentration of $20 \mathrm{~g} / \mathrm{L}$ in the $\mathrm{K}_{2} \mathrm{SO}_{4}$ and $\mathrm{KCl}$ solution. As the salt concentration increased, the UCST increased and then decreased. When poly(DMAAPS) was dissolved in the $\mathrm{K}_{2} \mathrm{SO}_{4}$ solution, with a low concentration of $0.001 \mathrm{~mol} / \mathrm{L}$, the UCST increased to around $57^{\circ} \mathrm{C}$.
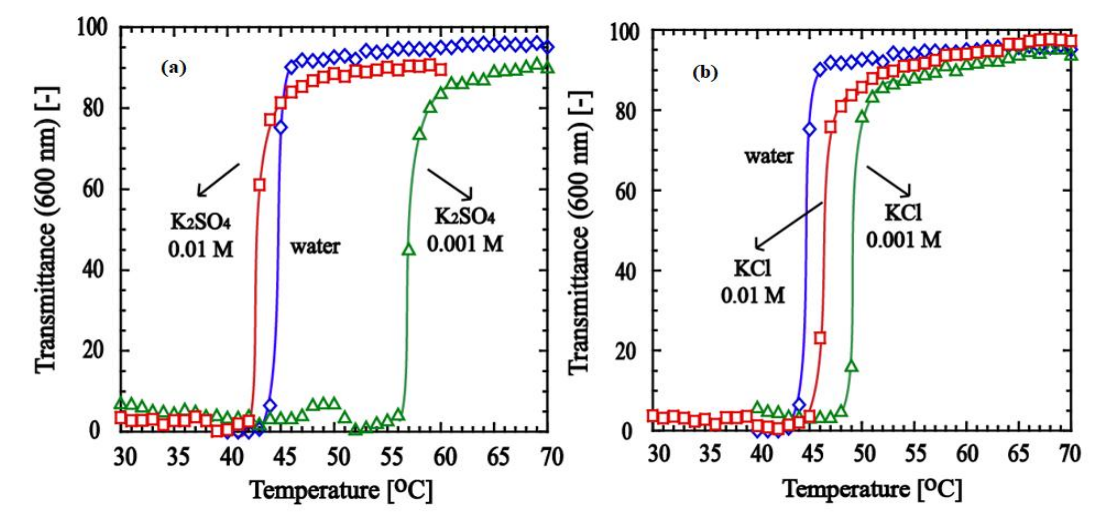

Figure 2 Transition behavior of poly (DMAAPS) in various concentrations of: (a) $\mathrm{K}_{2} \mathrm{SO}_{4}$; and (b) $\mathrm{KCl}$ solutions with polymer concentration of $20 \mathrm{~g} / \mathrm{L}$ 
This phenomenon was due to the partial dissociation of $\mathrm{N}^{+}$and $\mathrm{SO}_{3}{ }^{-}$pairing resulting from the new ionic interaction between the ions of the $\mathrm{K}_{2} \mathrm{SO}_{4}$ solution, i.e. $\mathrm{SO}_{4}{ }^{2-}$ and $\mathrm{K}^{+}$, and the charge groups of poly(DMAAPS), i.e. $\mathrm{SO}_{3}{ }^{-}$and $\mathrm{N}^{+}$. Part of the $\mathrm{N}^{+}$and $\mathrm{SO}_{3}{ }^{-}$groups on the DMAAPS gel network interacted with $\mathrm{SO}_{4}^{2-}$ and $\mathrm{K}^{+}$in the solution, respectively. Since the concentration was low, the number of ions available to break the inter- and/or intra-chain interaction of $\mathrm{N}^{+}$and $\mathrm{SO}_{3}{ }^{-}$groups in poly(DMAAPS) was limited, therefore the ionic pairing dissociation occurred partially. This partial dissociation induced chain mobility and promoted more chain entanglement, which led to the aggregation of the polymer.

However, a further increase in solution concentration to $0.01 \mathrm{~mol} / \mathrm{L}$ led to the solution transparency changing, making the UCST decrease from $57^{\circ} \mathrm{C}$ to around $43^{\circ} \mathrm{C}$. In the case of a high concentration of $\mathrm{K}_{2} \mathrm{SO}_{4}$ solution, due to the high number of ions attributed to breaking the inter- and/or intra-chain association, the dissociation of ionic pairing was more effective than those in low concentrations. Since the ionic pairing dissociation was high, soluble polymer chains were obtained. This phenomenon is in line with Ning et al.'s (2013) explanation, that the UCST of the solution decreases because of the ionic pairing dissociation.

Similar transition behavior was obtained when poly(DMAAPS) was dissolved in KCl solutions (Figure 2b). It is necessary to point out that although the tendency of the UCST of poly(DMAAPS) is quite similar, the effect of the ions from $\mathrm{KCl}$ to the UCST is relatively quiet minor in comparison to that in the $\mathrm{K}_{2} \mathrm{SO}_{4}$ solution.

\subsubsection{Effect of cation species}

The thermosensitive behavior of poly(DMAAPS) in salt solutions of $\mathrm{NaNO}_{3}, \mathrm{Zn}\left(\mathrm{NO}_{3}\right)_{2}$ and $\mathrm{Al}\left(\mathrm{NO}_{3}\right)_{3}$ are presented in Figures $3 \mathrm{a}-3 \mathrm{c}$. When sodium nitrate was added to the poly(DMAAPS) solution, the UCST first increased and then decreased, as shown in Figure 3a.
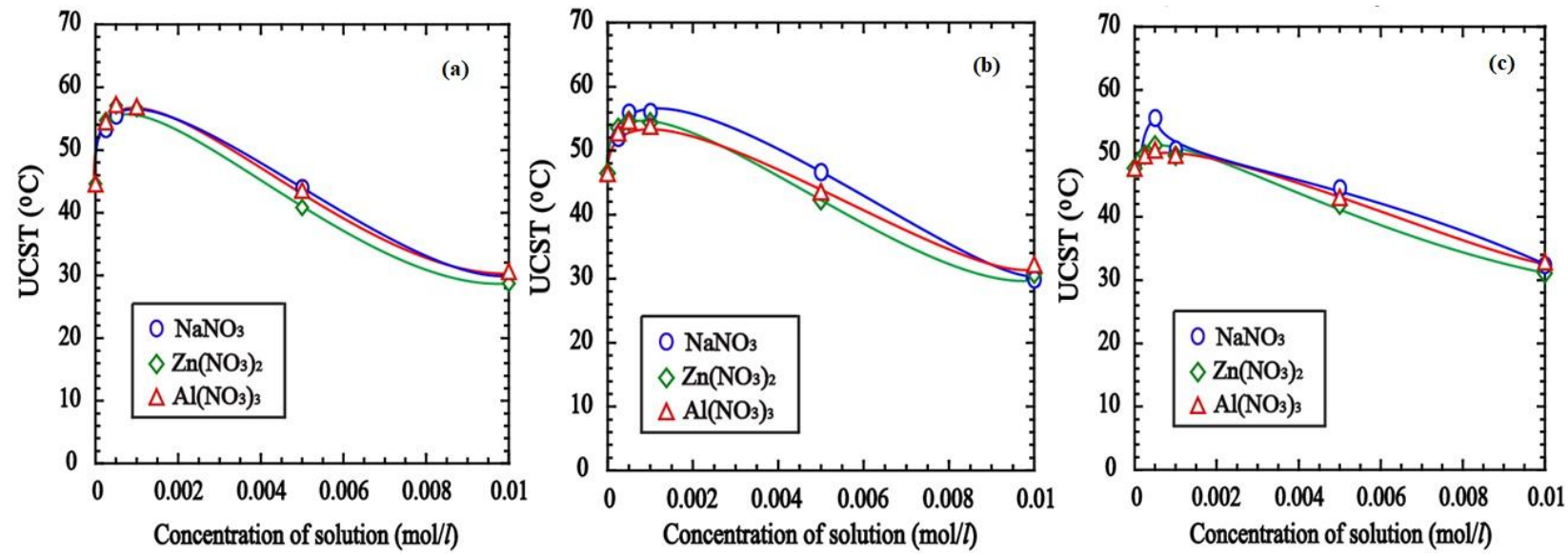

Figure 3 UCST of the poly(DMAAPS) in salt solutions of various polymer concentrations:

(a) $20 \mathrm{~g} / \mathrm{L}$; (b) $40 \mathrm{~g} / \mathrm{L}$; (c) $60 \mathrm{~g} / \mathrm{L}$

As can be seen from Figure 3a, initially, when poly(DMAAPS) was dissolved in the $\mathrm{NaNO}_{3}$ solution at a low concentration of $0.00025 \mathrm{~mol} / \mathrm{L}-0.001 \mathrm{~mol} / \mathrm{L}$, the polymer solution changed color to opaque or milky white, and the UCST was high at around $55^{\circ} \mathrm{C}$, which indicates that the polymer had a more dense network of entanglements. This was considered to be due to partial dissociation of the ionic pairing/inter-chain association of the DMAAPS chain as a result of the new ionic interaction between the ions in the solution and the betaine polymer. Part of the positive and negative charges on the DMAAPS gel network, $\mathrm{N}^{+}$and $\mathrm{SO}_{3}{ }^{-}$, interacted with $\mathrm{NO}_{3}{ }^{-}$ and $\mathrm{Na}^{+}$in the solution, respectively. The local rupture of the inter-chain association of the zwitterionic groups promoted more entanglement of the polymer chains, which made the polymer coil increase. 
However, a further increase in salt solution concentration to $0.005 \mathrm{~mol} / \mathrm{L}$ induced a change in the transparent solution and the UCST decreased from $55^{\circ} \mathrm{C}$ to around $40^{\circ} \mathrm{C}$. Meanwhile, in the high concentration salt solution, the ionic pairing dissociation was far more effective than at low concentrations due to the number of ions that could be attributed to inter-chain bonding rupture being higher. With this great dissociation of ionic pairing, a soluble polymer chain dispersed in the salt solution was obtained. This behavior is consistent with the results of Ning et al. (2013). In the aqueous $\mathrm{NaCl}$ solution, the inter-chain interaction within the zwitterionic groups was broken because of new ionic interaction between the group and the salt $\mathrm{Na}^{+}$and $\mathrm{Cl}^{-}$ions, resulting in the adsorption of the poly(DMAAPS) causing polymer dissolution even below the UCST.

Fairly similar phase transition behavior was also observed when the polymer was dissolved in $\mathrm{Zn}\left(\mathrm{NO}_{3}\right)_{2}$ or $\mathrm{Al}\left(\mathrm{NO}_{3}\right)_{3}$ solution. It should be pointed out that although the betaine gel charge groups interacted more strongly with the ions with higher valence, there was no significant difference between the UCST of the poly(DMAAPS). As previously explained, the higher ability of the cation, especially divalent and trivalent, to form bridges between sulfonates results in the formation of a short spacing between the polymer chains and as a consequence, the dissociation of the polymer chain is lower than or comparable with the chain entanglement. This leads to the greater thermal energy required to dissociate unfavorable ionic pairings.

\subsection{The Number of Ions Adsorbed onto the DMAAPS Gel}

\subsubsection{Effect of cation species}

This section describes the examination conducted on the effect of types of cation on the adsorption amount of cation onto the DMAAPS gel. Figure 4 shows the adsorption level of ions onto the DMAAPS gel from nitrate, chloride and sulfate solutions. This indicates that the amount of $\mathrm{Zn}^{2+}$ adsorption from the nitrate solution onto the DMAAPS gel was the highest among all the cations.
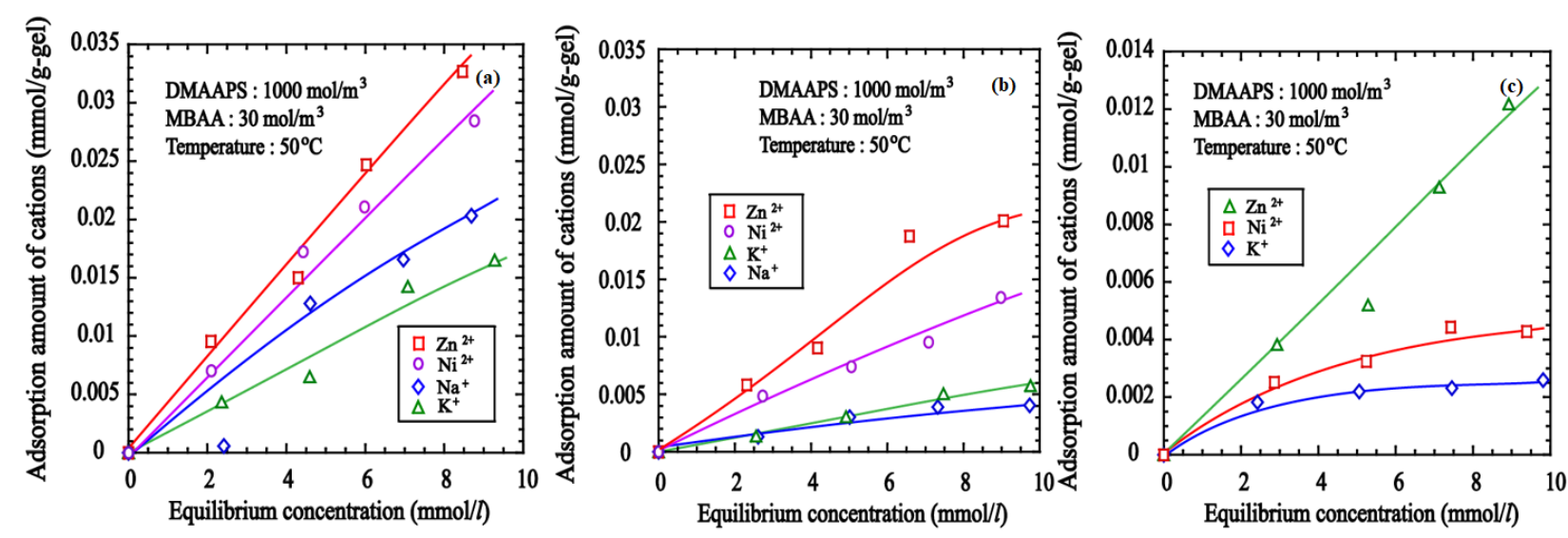

Figure 4 Adsorption level of various cations onto the DMAAPS gel in salt solutions of :(a) nitrate; (b) chloride; and (c) sulphate, at various concentrations at $50^{\circ} \mathrm{C}$

The order of adsorption was $\mathrm{Zn}^{2+}>\mathrm{Ni}^{2+}>\mathrm{Na}^{+}, \mathrm{K}^{+}$. This adsorption behavior is also consistent with DMAAPS gel treated with chloride and sulfate solutions. When DMAAPS gel is dipped into a solution containing ions with higher valences, it is easier for the ions to bind to the DMAAPS ammonium groups. This means that the adsorption ability of DMAAPS towards cation increases with the increase in the valences of cations. Ions with a smaller radius and lower valences have a low attraction to sulfonate groups of poly(DMAAPS), thus stronger interaction can take place between the ionic groups of the DMAAPS gel and ions with a larger radius and higher valence, causing adsorption order $\mathrm{Zn}^{2+}>\mathrm{Ni}^{2+}>\mathrm{Na}^{+}, \mathrm{K}^{+}$. This outcome is in accordance with Pearson's 
principle, in which soft acids have the tendency to bind with soft bases, while hard acids have the tendency to bind with hard bases (both hard species of acids and bases are usually small and slightly polarizable, while soft acids and bases are usually large and highly polarizable).

\subsubsection{Effect of anion species}

The amount of cations adsorbed onto the DMAAPS gel as a function of the equilibrium concentration of various salt solutions with different anion species is shown in Figure 5. The amount of anions adsorbed onto the DMAAPS gel was affected both by the cation concentration in the initial solution and the anion species type. The order of the amount of cations adsorbed was $\mathrm{NO}_{3}{ }^{-}>\mathrm{Cl}^{-}>\mathrm{SO}_{4}{ }^{2-}$, while the order of anions adsorbed was the reverse of the Hofmeister series. The anion series order is usually in the form of:

$$
\mathrm{CO}_{3}{ }^{2-}>\mathrm{SO}_{4}{ }^{2-}>\mathrm{S}_{2} \mathrm{O}_{3}{ }^{2-}>\mathrm{H}_{2} \mathrm{PO}_{4}{ }^{-}>\mathrm{F}^{-}>\mathrm{Cl}^{-}>\mathrm{Br}^{-} \approx \mathrm{NO}_{3}{ }^{-}>\mathrm{I}^{-}>\mathrm{ClO}_{4}{ }^{-}>\mathrm{SCN}^{-}
$$

This series is affected by the ability of anions to interact directly with positively charged groups of DMAAPS, $\mathrm{N}^{+}$, and their adjacent hydration shells. There are two species in this series, namely kosmotropes and chaotropes. Komostropes are the species on the left-hand side of the Hofmeister series, which are also called the "water-structure makers", while chaotropes are on right-hand side of the Hofmeister series, and are also known as "water-structure breakers". The anions of the kosmotropes are small and strongly hydrated, as opposed to the chaotropes, which are large and less hydrated. Chaotropes in the form of $\mathrm{NO}_{3}{ }^{-}$and $\mathrm{Cl}^{-}$ions were used in this research as weaker resistance to dehydration in the following order: $\mathrm{NO}_{3}{ }^{-}>\mathrm{Cl}^{-}$. Thus, greater adsorption took place when the DMAAPS gel was adsorbed in a nitrate solution, and the $\mathrm{NO}_{3}{ }^{-}$ions interacted with the DMAAPS $\mathrm{N}^{+}$groups strongly. This is different from the $\mathrm{SO}_{4}{ }^{2-}$ ions, which are kosmotropes, building a stronger interaction with the water molecules than the cohesive forces of such molecules, since the ions belong to a hydrated species. Therefore, less interaction occurs between $\mathrm{SO}_{4}{ }^{2-}$ ions and the $\mathrm{N}^{+}$of DMAAPS because $\mathrm{SO}_{4}{ }^{2-}$ remains hydrated, causing lower adsorption.

The independence of the adsorption on the cation species also shows the ion selectivity of the tested cations on the $\mathrm{SO}_{3}{ }^{-}$of DMAAPS. In addition, by comparing the effect of anion and cations of the same charge on the adsorption level, the anion species effect is greater than that of the cation species at all concentrations.
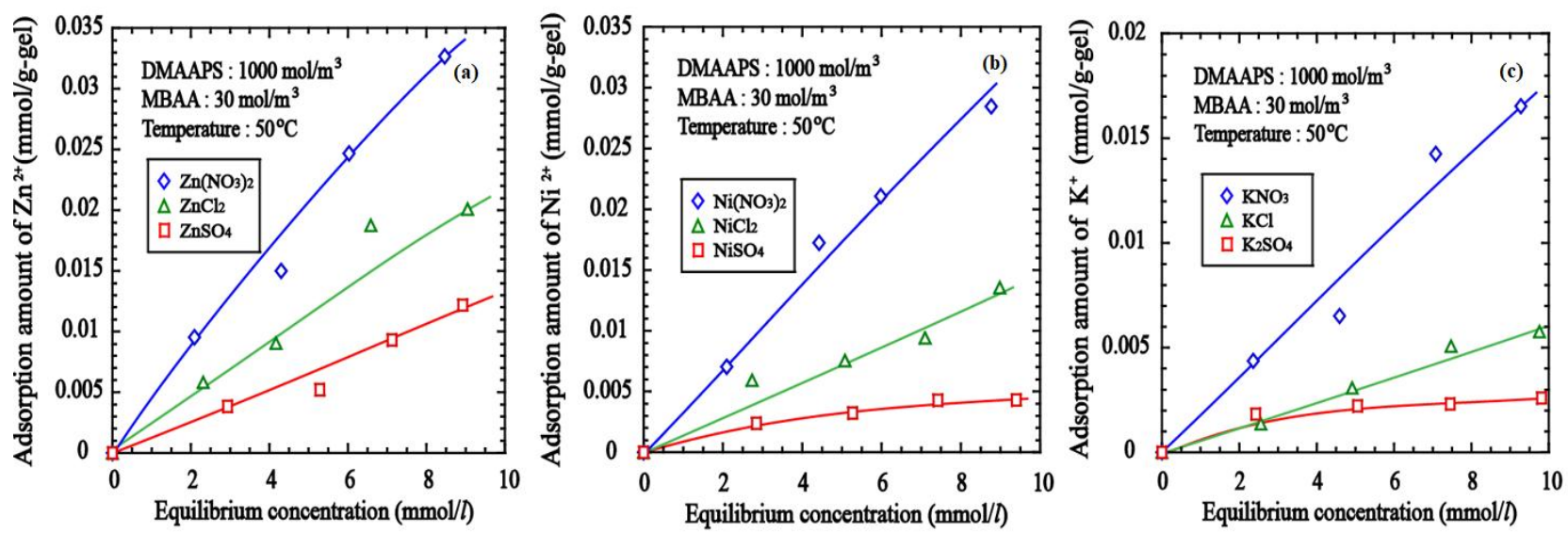

Figure 5 Adsorption amount of: (a) $\mathrm{Zn}^{2+}$; (b) $\mathrm{Ni}^{2+}$; and (c) $\mathrm{K}^{+}$onto the DMAAPS gel in various salt solutions at $50^{\circ} \mathrm{C}$ 


\section{CONCLUSION}

The transition and ion-adsorption behavior of DMAAPS gel and polymer have been investigated in nitrate, chloride and sulfate solutions. The aqueous solution of the poly(DMAAPS) exhibited an upper critical solution temperature (UCST) in a salt solution, and with the increase in salt concentration, the UCST first increased and then decreased. The adsorption behavior of cations in the nitrate, chloride and sulfate solutions was found to be a strong function of the valence, with the order of adsorption being $\mathrm{Zn}^{2}+>\mathrm{Ni}^{2}+>\mathrm{Na}^{+}, \mathrm{K}^{+}$. The number of ions adsorbed onto the DMAAPS gel in various salt solutions with a common cation of $\mathrm{Na}^{+}, \mathrm{K}^{+}$and $\mathrm{Zn}^{2+}$ shows a tendency in the order of $\mathrm{NO}_{3}{ }^{-}>\mathrm{Cl}^{-}>\mathrm{SO}_{4}{ }^{2-}$.

\section{ACKNOWLEDGEMENT}

This research was supported financially by a Penelitian Kerjasama Luar Negeri 2018 (952/PKS/ITS/2018) research grant for ten consecutive months from Direktorat Jenderal Penguatan Riset dan Pengembangan Kemenristekdikti.

\section{REFERENCES}

Baldino, L., Cardea, S., Reverchon, E., 2016. Loaded Silk Fibroin Aerogel Production by Supercritical Gel Drying Process for Nanomedicine Applications. Chemical Engineering Transactions, Volume 49, pp. 343-348

Graillot, A., Bouyer, D., Monge, S., Robin, J.-J., Faur, C., 2012. Removal of Nickel Ions From Aqueous Solution by Low Energy-consuming Sorption Process Involving Thermosensitive Copolymers with Phosphonic Acid Groups. Journal of Hazardous Materials, Volume 244245, pp. 507-515

Kusrini, E., Kinastiti, D.D., Wilson, L., Usman, A., Rahman, A., 2018a. Adsorption of Lanthanide Ions from an Aqueous Solution in Multicomponent Systems using Activated Carbon from Banana Peels (Musa Paradisiaca L.). International Journal of Technology, Volume 9(6), pp. 1132-1139

Kusrini, E., Sakadewa, O., Pasca, G., Usman, A., Yulizar, Y., 2018b. Selective Adsorption of Textile Dyes using Pre-treated Graphite Waste and Graphite/ $\mathrm{Fe}_{3} \mathrm{O}_{4}$ Composites. In: IOP Conference Series: Materials Science And Engineering. IOP Publishing, 012029, Volume 440 ,

Kusrini, E., Usman, A., Wibowo, J., 2019. SnOx-Impregnated Clinoptilolite for Efficient Mercury Removal from Liquid Hydrocarbon. Arabian Journal for Science and Engineering, Volume 44, pp. 189-197

Neagu, V., Vasiliu, S., Racovita, S., 2010. Adsorption Studies of Some Inorganic and Organic Salts on New Zwitterionic Ion Exchangers with Carboxybetaine Moieties. Chemical Engineering Journal, Volume 162(3), pp. 965-973

Nesterenko, E.P., Nesterenko, P.N., Paull, B., 2009. Zwitterionic Ion-exchangers in Ion Chromatography: A Review of Recent Developments. Analytica Chimica Acta, Volume 652(1-2), pp. 3-21

Ning, J., Kubota, K., Li, G., Haraguchi, K., 2013. Characteristics of Zwitterionic Sulfobetaine Acrylamide Polymer and the Hydrogels Prepared by Free-radical Polymerization and Effects of Physical and Chemical Crosslinks on the UCST. Reactive and Functional Polymers, Volume 73(7), pp. 969-978

Ningrum, E.O., Murakami, Y., Ohfuka, Y., Gotoh, T., Sakohara, S., 2014. Investigation of Ion Adsorption Properties of Sulfobetaine Gel and Relationship with Its Swelling Behavior. Polymer, Volume 55(20), pp. 5189-5197 
Ningrum, E.O., Ohfuka, Y., Gotoh, T., Sakohara, S., 2015. Effects of Specific Anions on the Relationship between the Ion-adsorption Properties of Sulfobetaine Gel and Its Swelling Behavior. Polymer, Volume 59, pp. 144-154

Ningrum, E.O., Purwanto, A., Mulyadi, E.O., Dewitasari, D.I., Sumarno, S., 2017a. Adsorption and Desorption of $\mathrm{Na}^{+}$And $\mathrm{NO}_{3}{ }^{-}$Ions on Thermosensitive NIPAM-co-DMAAPS Gel In Aqueous Solution. Indonesian Journal of Chemistry, Volume 17(3), pp. 446-452

Ningrum, E.O., Purwanto, A., Ni'mah, H., Sumarno, Dewitasari, D.I., Mulyadi, E.O., 2017b. Ion Adsorption and Desorption Behaviors of Thermosensitive NIPAM-co-DMAAPS Gel by Temperature Swing. In: AIP Conference Proceedings, 1840, 090007

Nonaka, T., Hua, L., Ogata, T., Kurihara, S., 2003. Synthesis of Water- soluble Thermosensitive Polymers Having Phosphonium Groups from Methacryloyloxyethyl Trialkyl Phosphonium Chlorides-N- Isopropylacrylamide Copolymers and their Functions. Journal of Applied Polymer Science, Volume 87(3), pp. 386-393

Todaro, S., Sabatino, M., Ajovalasit, A., Ditta, L., Castiglia, D., Wach, R., Ulanski, P., Bulone, D., Dispenza, C., 2016. Radiation Engineering of Xyloglucan Hydrogels. Chemical Engineering Transactions, Volume 49, pp. 289-294 